tional employés shall not exceed four principal examiners, four first assistant examiners, four second assistant examiners, eight third assistant examiners, eignt fourth assistant examiners, four first-class clerks, four copyists, six laborers, six assistant messengers and six messenger six laborers, six assistant messengers and six messenger
boys. It will be admitted, we think, that the business boys. It will be admitted, we think, that the business
of the Patent Office has been looked into with great atof the Patent Office has been looked into with great attention to detail when so modest an appropriation
therefor is so specifically guarded. But we hope that, with such inspection of the business, it did not fail to impress itself upon the members of the Committees on Patents of both branches of Congress that the present quarters occupied by the entire force for the prosecution of their work and the keeping of the necessary re cords are altogether too cramped and overcrowded for the attainment of the best degree of efficiency. More room an 1 better facilities, especially a well equipped
laboratory, are quite as urgently called for as the addilaboratory, are quite as urgently called

tional force of examiners, clerks, etc.

The especial reason for bringing forward this bill at present is found, not in the well-known fact that the Patent Office has been overworked for years, and the issue of patents thereby greatly delayed, but in the need which has arisen, as a consequence of the act of tion, by subjects matter, of all letters patent and tion, by subjects matter, of all letters patent and printed publications which "constitute the field of
search in the examination as to the novelty of invensearch in the examination as to the novelty of inven-
tion for which applications for patents are or may be filed." It is now made especially the duty of the
Patent Office to see that an invention for which appliPatent Office to see that an invention for which application for a patent is made shall not be patented or ' before the invention made by the applicant, and, ac cording to the report of Mr. Hicks, it is the intention by this appropriation to enable the Commissioner of Patents "to make examinations in a manner so thorough and complete as to insure the issuance of patents only for such inventions as are unquestionably new ; so that the patent when issued shall be an affirmative statement, certified to under the seal of the Patent
Office, that the invention covered thereby is new, and Office, that the invention covered thereby is new, and
has not been described in any patent or printed publication." It will be seen, therefore, that the design is to enable the Patent Office to make competent examinations of the whole field of in vention-embracing more of technical publications-the effort to do which is already constituting a great drag on the work of the office, which is now from two to seven months in arrears, and it being evident that " the office is strug. gling with a load much too heavy for it to carry." The Commissioner expects that, with the additional appropriation, "the income of the office will be greatly increased by the more rapid and thorough disposal of the business and the increased number of applications them will be prompt and thorough."

\section{THE FRUITS OF CIVIL SERVICE REFORM}

Civil service reform has now been on its trial for period of about fifteen years, and each succeeding year has given stronger proof of its value in the practical re-
sults which have been achieved. In its recent annual report the Civil Service Commission points out that the merit system, as compared with the patronage system, is both more economical and more efficient. This is conclusively shown in a comparison of the few changes the many removals under the patronage system. During five years preceding the classification of the New York Custom House there was an average of 275 reYork Custom House there was an average of 275 re-
movals per year, whereas during the past two years the movals per year, whereas during the past t wo years the removals averaged only 50 per year and the resignations
30 per year. The figures for the civil service of the whole country are even more conclusive, for 75 per cent of
those holding unclassified positions were removed those holding unclassified positions were removed,
while in the classified competitive service only 85 resigned. During the fifteen years of civil service reform the positions which are politically controlled have increased 37 per cent in number and 43 per cent in cost, while the number of classified positions not subject to such control has remained the same. The economy of the merit system is further illustrate by the fact that the merit system is further illustrated by the fact that
the extension of the civil service rules in May of last
year, by which a large number of hitherto unclassified year, by which a large number of hitherto unclassified
positions were brought under the merit system, led to positions were brought under the merit system, led to
the abolishing of a number of positions which wer found to be quite unnecessary.

In spite of the objection which has been urged against the merit system, on the ground that it renders employes too independent and encouraged carelessness in the President in July of last year which prohibits the President in July of last year which prohibits
removals except for cause and upon written charges. removals except for cause and upon written charges.
On the general question we think that it is very doubtful if any serious trouble of this nature has ever arisen.
If it has, it is immensely outweighed by the excellent results which have been secured, and it is a fact that the new rule has met with general public approval. It is argued that while the new rule in no way interferes with guards against unjust removals, and insures that per- wanence in office shall depend upon efficiency and

One of the strongest arguments against the political ystem is that the tenure of office is for only a limited number of years, and the appointments being made on strictly political considerations, the new incumbent may or may not have any qualifications for the specialduties
of his position. An equally serious dra wback is the fact that the return of a political party to office is certain to deprive the government of the services of a greater or less number of employes who, during their service, have acquired valuable experience and efficiency. These
points are dwelt upon at considerable length by the commission, who recommend that the scope of the civil service law he extended to embrace all positions to which it could be applied with advantage. It is specifically suggested that the municipal service of
the District of Columbia, the staff of the Congressional the District of Columbia, the staff of the Congressional
Library, and the clerical force of the next census be brought under the civil service law.

Apart from the abstract principles involved in the question of removing the civil service from the field of politics, with which in the nature of things it has no are of the highest importance. This is evident when we bear in mind that the total salaries paid out annully to the employes in the executive civil service mount to close upon $\$ 100,000,000$. Bearing in mind the statement in the report already referred to, that nce 1882, the year of the organization of the committee, the unclassified positions under political control
have increased in cost 43 per cent while the classified positions have remained the same, it will be seen that nances of reform has an important bearing upon the xecutive civil service shown by a census of them taen last year, about one-half were in positions which were governed by the rules of the civil service.

\section{THE HEAVENS IN APRIL.}

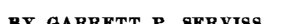

The mild nights of early spring are adorned with onstellations less brilliant than those of winter, but not less beautiful. Orion and Taurus appear, in the wilight, robbed of the dazzling brightness that charcterized them when they were on the meridian in midwinter. Higher up glows Capella with a softened radiance, while the Milky Way stretches, like a vernal head, south of the zenith, is Leo, and north of the enith the Great Dipper. Virgo is conspicuous in the Cast, and Arcturus, high and splendid, counterbalances Capella on the other side of the meridian, while, as
Sirius is setting in the southwest, the Sirius of the Sirius is setting in the southwest, the Sirius
orth, Vega, appears rising in the northeast. THE PLANETS.

Mercury is an evening star, and there will be no better opportunity to see it this year than that presented about the 10th of April, when it will attain its greatest elongation east of the sun, and will not set until almost two hours after sundown. At the beginning of the
month Mercury is in Pisces; at theend, when it passes motw Mercury is in Pisces; at theend,

Venus also is an evening star, and gradually becoming more conspicuous, as it moves out of the neighborhood of the sun. It is not far west of Mercury at the pening of April, but, after the latter turns in its planets will draw nearer together, coming into conjunction on the 18th, when Mercury will appear between three and four degrees north of Venus. From tween three and four degrees north of Venus. From
that time on Mercury will cease to be a conspicuous bject in the sunset sky, leaving Venus to reign alone here. Notwithstanding Mr. Percival Lowell's much exploited observations and theories, there is, as yet, no
good reason for not regard ing Venus as the most earthlike of all the planets that circulate within or without the orbit of our terraqueous ball. The observations of it to be made during the present year should be of ininse interest. At the beginning of the month Venu Mars is in the morning sky, and still too near the un for easy or satisfactory observation. It moves in Pisces and Cetus.

Jupiter in Virgo, near the star Eta, is a magnificent sight for all who can appreciate the wonder and beauty of celestial phenomena. Recent telescopic study has revealed the formation of new spots among its great ject for the possessor of a telescope. It rises before sunset, and, as the evening advances, moves up the eastern sky clothed with the majesty proper to the ightiest of the planets.

"What is that bright star?" asked a man who never "ooks at the heavens except by chance.

"The planet Jupiter."

"Why, I never saw such a star! Do they often look " "What?"

For a very full description and illustration of these
Possessors of telescopes may watch interesting phenomena of Jupiter's satellites on the night of the 17th. I CAN of January 29, 1898.

At 8:15 o'clock, Eastern standard time, Satellite I. will M. Satellite II. will begin to transit the er, and at 9:22 its shadow will follow the satellite upon the disk and will occupy two and a half hours in crossg it. On the night of the 28th an interesting obseration may be made showing the effect of the position of the sun on the direction of the shadows of Jupiter's
moons in relation to the line of sight between the earth Jupiter. At 7:34 P. M. Satellite III. will pass upon the disk and begin a transit which will end at $0: 15$. But the shadow of the satellite will be so inclined to ourline of sight that it will not appear on the has completed the transit.

Jupiter is very close to the celestial equator, and rosses it, moving northward on the 8th.

Saturn, whose rings are now admirably placed for observation, can be seen in the east, rising at the end
of the month near 9 o'clock; but it will be much better situated for evening observation in May. It is in Ophichus, near Scorpio.

Uranus is near a little pair of stars, the Omegas, in corpio, and gradually gets closer to them in the course urn. Its approach to the Omegas will be interesting to watch with a field glass or a small telescope.

Neptune, invisible to the naked eye, remains in aurus.

The moon is full on the afternoon of the 6th of April, and in last quarter on the morning of the 13th. The new moon of April occurs on the afternoon of the The moon is nearest the earth on the 9 th and farthest rom it on the 25th.

The greatest eastern libration occurs on the evening ing of the 17th.

The moon's conjunctions with the planets occur as Tllows:

Jupiter on the 5th, Uranus on the 9th, Saturn on on the 21st, Neptune on the 24th

There are several recognized meteoric showers in April, of which one, occurring on the 2uth, may be few degrees west of the brilliant Vega, in the constellation Lyra

\section{FORTHCOMING TELEGRAPHIC TOURNAMENT}

During the electrical exposition which is to take
place at Madison Square Garden during the month of May, the Board of Control will hold a Fast Sending and Receiving Tournament which is intended to surAs at present arranged, the events include

A message class for receivers, transmission thirty inutes, receivers to use typewriters of their selection. ovice class, open to persons not having an officia ecord; sending five minutes. Championship class, ceivers. Ladies' class, free for all, sending five minutes. Two-forty-word class, open to those not having an official record of 240 words or better, sending five minutes. Two-thirty-five-word class, open to all who have not an official record of two-thirty-five words or better, sending five minutes. Two-thirty-word class, open to
all who have not an official record of two-thirty word or better, sending five minutes. Two-twenty-five-word class, open to all who have not an official record of twotwenty-five words or better, sending five minutes. The judges of the contest will include leading officials of the great telegraph companies and the editors of several leading electrical papers.

The best official records in contests of this kind were
made in 1893, F. J. Kihm and F. L. Catlin sending 248 made in 1893, F. J. Kihm and F. L. Catlin sending 248 words without an error, and R. C. McCready sending

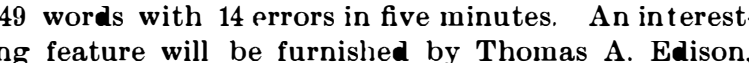
who will make a phonographic record of the best transmissions, thus enabling contestants to listen at transmissions, thus enabling contestants
any time to the record of their own work.

\section{LAUNCH OF THE BATTLESHIPS "KEARSARGE" AND} On Thursday, March 24, there were launched at the Newport News shipbuilding yard the two most power-
ful ships of the United States navy, the "Kearsarge" " and "Kentucky." They are an improvement upon the "Indiana " class, which they exceed in size, speed and ment and 16 knoth. They are of 11,525 tons displace $16 \frac{1}{2}$ inches of steel on the belt and 15 inches on the barbettes and turrets. The main battery consists of barbettes and turrets. The main battery consists of
four 13 -inch and four 8 -inch guns, and there will be four 13 -inch and four 8 -inch guns, and there will be
fourteen 5 -inch guns in the secondary battery. The most remarkable feature of these ships is the doubledeck turrets, the 8 -inch guns being mounted above the 13-inch

hips the reader is referred to the SCIENTIFIC AMERI- 